\title{
Effect of the annealing procedure and the molecular weight on the crystalline phase morphology and thermal properties of polylactide.
}

Thermal annealing as a strategy to improve the properties of polylactide

\author{
Martí Hortós $^{1,3}$, Jon Anakabe ${ }^{2}$, Alex Arrillaga², Sebastián Espino ${ }^{3}$, Jordi J. Bou ${ }^{1 *}$ \\ 1 Universitat Politècnica de Catalunya/ETSEIB/Departament d'Enginyeria Química. Avinguda \\ Diagonal, 647, 08028 Barcelona (Spain) \\ 2 Leartiker S. Coop., Xemein etorbidea 12, 48270 Markina-Xemein (Spain). \\ 3 Ercros S.A., Departamento de I+D. Avinguda Diagonal, 595, 08014 Barcelona (Spain). \\ E-mail: jordi.bou@upc.edu
}

\begin{abstract}
The thermomechanical properties of poly(lactide) (PLA) are strongly related to its semicrystalline microstructure and morphology. The thermal annealing is a strategy to improve the crystallinity of PLA. However, the different techniques and specimen types needed for each kind of characterization could lead to misleading conclusions. In this work, annealed samples of three PLA grades with different molecular weights have been studied by Differential Scanning Calorimetry (DSC), Wide Angle X-Ray Scattering (WAXS) and Polarized optical Microscopy (POM) and related to their thermomechanical and impact properties. Special focus has been put on POM results obtained by different approaches and the suitability of each of them in order to be related to the thermomechanical properties. By annealing medium molecular weight PLA specimens at $140{ }^{\circ} \mathrm{C}$ an important increase of the Heat Distortion Temperature (HDT) value was obtained, which was not related to the obtained spherulite size but to the combination of high crystallinity degree together with high $\alpha / \alpha^{\prime}$ crystal type ratio. However, impact properties of annealed PLA decreased with increasing the annealing temperature according to an increment of crystallinity and $\alpha / \alpha^{\prime}$ crystal ratio.
\end{abstract}

Keywords: Polylactide, molecular weight, annealing, crystalline morphology 


\subsection{Introduction}

Biobased polymers have the great advantage of using renewable raw materials. Besides, some of them enable end-of-life waste management alternatives like composting or anaerobic digestion, hence reducing landfilling or toxic gas emissions (incineration). Some of these biobased polymers are already largely commercialized, such as poly(lactic acid) (PLA). This bioplastic is available in large volume (the worldwide production is around $200 \mathrm{kt} / \mathrm{year}$ ) for various applications such as packaging, electronic housing, textile, automobile, insulation in building, or even biomedical ${ }^{1-}$ 3 .

Due to the chiral nature of lactic acid ( $\mathrm{L}$ and $\mathrm{D}$ ) and the corresponding lactides, different PLA architectures can be obtained by ring opening polymerization. Crystallization kinetics, maximum degree of crystallization and melting temperature of PLA are strongly dependent on the L- to Dlactic content ratio ${ }^{4-6}$. According to the L/D ratio, amorphous or semi-crystalline PLA can be synthesized and, consequently, strong variations on thermal, mechanical and barrier properties can be obtained ${ }^{7,8}$. On the other hand, molecular weight has also been shown to affect the crystallization behaviour of PLA ${ }^{9,10}$.

The combination of different techniques such as DSC, WAXS and POM has been extensively used in order to obtain new insight on the semicrystalline structure of annealed PLA ${ }^{9-15}$. However, the need of different kind of samples for each technique could lead to unintentional mistakes and misleading conclusions.

This work aims to understand the effect of the annealing process carried out at different conditions (starting temperature, annealing temperature and heating rate) on the micromorphology and crystalline structure of three different molecular weight PLA grades. POM results obtained by different sample preparation and annealing processes including microtomized samples of the specimens used for mechanical characterization are shown and related to DSC, WAXS, HDT and impact resistance results.

\subsection{Experimental}

\subsubsection{Materials and sample preparation}

Three PLA grades from Ercros S.A. with different molecular weight were studied: ErcrosBio ${ }^{\circledR}$ LL600 $\left(\mathrm{M}_{\mathrm{n}}=70 \mathrm{~kg} \cdot \mathrm{mol}^{-1}, \mathrm{D}=2.37\right), \operatorname{LL650}\left(\mathrm{M}_{\mathrm{n}}=110 \mathrm{~kg} \cdot \mathrm{mol}^{-1}, \mathrm{D}=2.31\right)$ and LL700 $\left(\mathrm{M}_{\mathrm{n}}=140\right.$ $\left.\mathrm{kg} \cdot \mathrm{mol}^{-1}, \mathrm{D}=2.58\right)$. L-lactic acid content was similar for all of them ( $\left.>99.5 \%\right)$. Tensile test specimens (ISO-527) were obtained by injection moulding at an injection temperature of $210{ }^{\circ} \mathrm{C}$ and a mould temperature of $30^{\circ} \mathrm{C}$. Specimens were then annealed in an oven at 90, 105, 120140 ${ }^{\circ} \mathrm{C}$ for $1 \mathrm{~h}$. 


\subsubsection{Characterization techniques}

The average molar masses and the polydispersity of the PLA specimens were measured by SEC using a Waters Gel Permeation Chromatography (GPC) apparatus equipped with a Waters 410 differential ultraviolet detector.

The analyses were developed at room temperature and $0.8 \mathrm{~mL} \cdot \mathrm{min}^{-1}$ in hexafluoroisopropanol (HFIP) on a PLHFIPgel column (Polymer Laboratories Ltd). The calibration was performed with PMMA standards from 2000 to $500 \times 10^{3} \mathrm{~g} \cdot \mathrm{mol}^{-1}$. DSC analyses were performed by means of a Mettler Toledo DSC 3 Star System model. Samples of approximately $7 \mathrm{mg}$ were encapsulated in aluminium pans. The first heating at $10^{\circ} \mathrm{C} / \mathrm{min}$ from 30 to $200{ }^{\circ} \mathrm{C}$ was analysed to determine the crystallinity and the melting behaviour of the samples. In order to calculate the crystallinity degree, the theoretical melting enthalpy value for a 100\% crystalline PLA was estimated in 93.6 $\mathrm{J} / \mathrm{g}^{16,17}$. Wide-angle X-ray scattering (WAXS) spectra were recorded on a Bruker AXS D8 Advance system with $\mathrm{Cu} \mathrm{K} \alpha$ radiation of wavelength $\lambda=1.5406 \AA$ (Barcelona Research Center in Multiscale Science, UPC). A range of $2 \theta$ from $10^{\circ}$ to $30^{\circ}$ was recorded using a step size of $0.02^{\circ}$ per second on injection moulded specimens. The crystalline structure of the samples was analysed by polarized optical microscopy (POM) by means of a Nikon eclipse 80i optical microscope. Samples were prepared by two different methods. Pellets were molten into films between coverslips in a Linkam hot-stage in order to analyse the crystallization either after cooling from the melt and after heating amorphous samples from the glassy state. On the other hand, samples crystallized from the glassy state using previously injection moulded specimens were prepared by microtomy in order to retain the crystalline morphology and avoid thermal history erasing.

Dynamic Mechanical Analysis (DMA) was carried out in a DTMA Q800 instrument (New Castle, USA) applying a $0.02 \%$ deformation at a $1 \mathrm{~Hz}$ frequency by dual cantilever bending method. Specimens of $80 \times 10 \times 4 \mathrm{~mm}^{3}$ in size obtained from injection moulded plates were heated from 30 to $150{ }^{\circ} \mathrm{C}$ at a rate of $2{ }^{\circ} \mathrm{C} \cdot \mathrm{min}^{-1}$. Heat Distortion Temperature under $1.80 \mathrm{MPa}$ load (HDT-A) was measured using a Metrotec HDT-687 bath as defined by ISO 178 standard. Notched Charpy impact tests were carried out by means of an ATS faar IMPats-15 impact pendulum according to the ISO 179 standard with a $4 \mathrm{~J}$ hammer and a support span of $80 \mathrm{~mm}$.

\subsection{Results and discussion}

The effect of the annealing process on the molecular weight of PLA was studied by GPC. Figure 1 shows the chromatograms of each PLA grade before and after an annealing process for 1 hour at $140{ }^{\circ} \mathrm{C}$, the highest temperature and thus the most severe conditions applied in this study. No variation was detected after the annealing, indicating that the samples did not suffer noticeable degradation. 


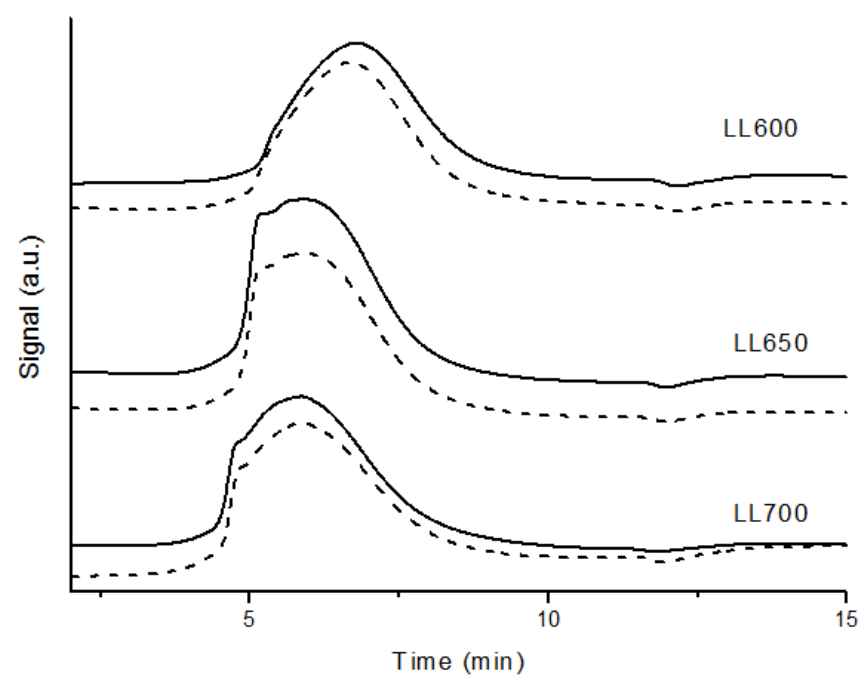

Figure 1. GPC chromatograms of different molecular weight PLA grades: before (solid) and after (dash) annealing at $140{ }^{\circ} \mathrm{C}$ for 1 hour.

\subsubsection{Crystalline structure}

The crystallinity degree of PLA bars (central inner section) annealed at different temperatures is presented in Table 1. LL600 and LL650 showed similar crystallinity degree $\left(\mathrm{X}_{\mathrm{c}}\right)$ after annealing at same temperatures, whereas LL700 showed lower values (Table 1). On the other hand, higher annealing temperatures led to higher crystallinity degrees for LL600 and LL650, especially at 140 ${ }^{\circ} \mathrm{C}$. This is in agreement with the results obtained by Pluta and Galeski ${ }^{11}$. However, LL700, which has the higher molecular weight among the studied PLAs, did not show any significant variation on its crystallinity degree due to different annealing temperatures. Indeed, the higher molecular weight PLA (LL700) reached its maximum value of crystallinity at $90{ }^{\circ} \mathrm{C}$ and therefore higher temperatures did not have any influence in terms of degree of crystallinity. This phenomenon can be justified by the fact that high molecular weight semicrystalline polymers present lower chain mobility and therefore their crystallization ability is limited.

Table 1. Crystallinity degree of PLA bars annealed at various temperatures.

\begin{tabular}{cccc}
\hline \multirow{2}{*}{ Annealing conditions } & \multicolumn{3}{c}{ Xc (\%) } \\
\cline { 2 - 4 } & LL600 & LL650 & LL700 \\
\hline As injection moulded & 25.5 & 27.0 & 20.0 \\
$90^{\circ} \mathrm{C}$ at $1 \mathrm{~h}$ & 50.9 & 48.4 & 45.4 \\
$105^{\circ} \mathrm{C}$ at $1 \mathrm{~h}$ & 47.9 & 43.8 & 43.7 \\
$120^{\circ} \mathrm{C}$ at $1 \mathrm{~h}$ & 55.5 & 57.0 & 43.7 \\
$140^{\circ} \mathrm{C}$ at $1 \mathrm{~h}$ & 63.0 & 61.6 & 45.8 \\
\hline
\end{tabular}


As a representative example, a DSC heating thermogram for LL600 crystallized at different annealing conditions is shown in Figure 2. All unannealed samples showed the $\mathrm{T}_{\mathrm{g}}$ at around 60$65{ }^{\circ} \mathrm{C}$ followed by a cold crystallization peak, indicating that PLA did not completely crystallize during the previous injection moulding. The peak temperature of the cold crystallization was 93, 97 and $100{ }^{\circ} \mathrm{C}$ for LL600, LL650 and LL700, respectively, which suggested that the lower the molecular weight was, the higher the crystallization rate of PLA ${ }^{9}$, No cold crystallization peak was detected for annealed samples indicating complete crystallization of PLA after 1 hour at 90, 105,120 or $140{ }^{\circ} \mathrm{C}$.

All samples showed the known dual-peak melting transition of PLA, the first peak being related to the $\alpha$ ' to $\alpha$ phase transition and the second one to the melting of the $\alpha$ crystals. ${ }^{11}$ The first peak ranged from 158 to $169{ }^{\circ} \mathrm{C}$ for annealing temperatures of 90 and $140{ }^{\circ} \mathrm{C}$, respectively. The subsequent melting peak of $\alpha$ crystals was detected between 176 and $181{ }^{\circ} \mathrm{C}$ for all samples, regardless the molecular weight. The existence of the two different crystal modifications $\alpha$ and $\alpha$ ' obtained at low and high crystallization temperatures respectively explains the dual-melting peak behaviour of PLLA, which has been thoroughly studied ${ }^{9,11,12,18-21}$.

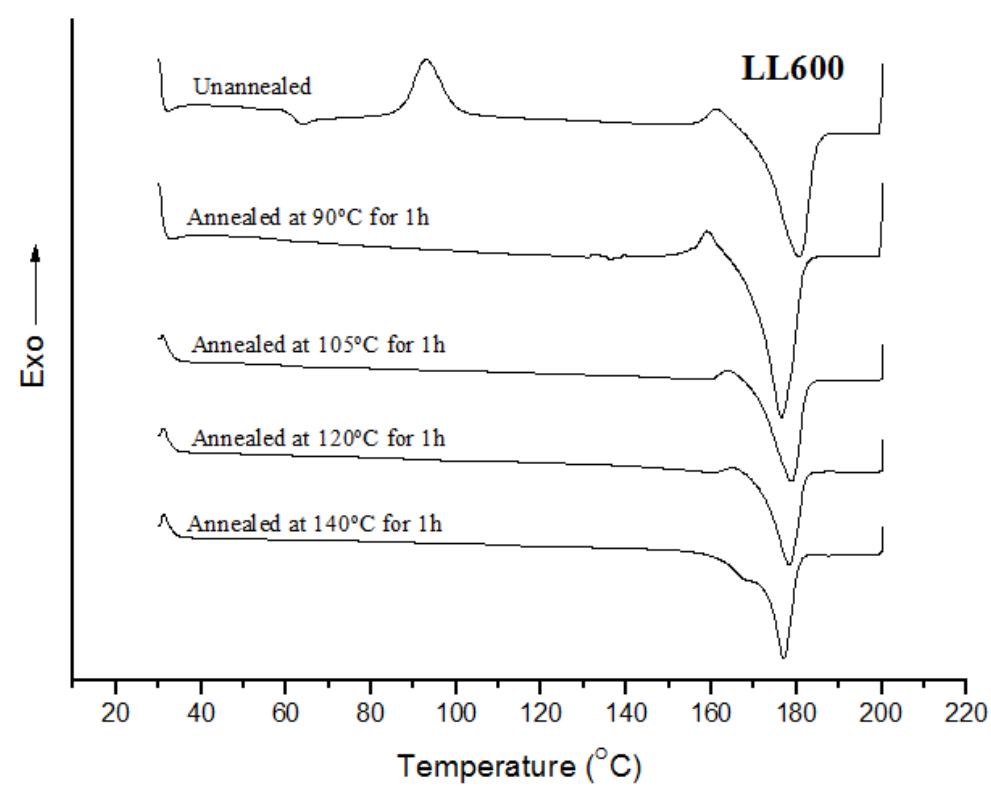

Figure 2. DSC heating thermograms of LL600 annealed for 1 hour at different temperatures.

The lower temperature melting peak shifted toward a higher temperature and became more endothermic with the increase of the annealing temperature, suggesting that at higher annealing temperatures the predominant crystal form developed was the $\alpha$, which is in agreement with literature ${ }^{22}$. Furthermore, this peak turned to be endothermic for LL600 and LL650 crystallized at $140{ }^{\circ} \mathrm{C}$. Hence, $\alpha^{\prime}$ crystallites formed at higher temperatures are more stable and their melting temperature is closer to that of $\alpha$ crystals, thus they cannot recrystallize again. On the contrary, higher molecular weight LL700 samples exhibited exothermic $\alpha$ '-to- $\alpha$ peaks regardless the 
annealing temperature, suggesting that less stable and more disordered crystallites might be formed due to the higher molecular weight and so lower molecular mobility of this PLA.

WAXS patterns showed that no diffraction peak was detected for the unannealed samples, suggesting that injection moulded specimens were completely amorphous. This result contrasted with the DSC results of the unannealed samples since they indicated that the specimens developed around $20-27 \%$ of crystallinity before the annealing process. Such differences could be due to different resons, including a higher sensitiveness to low crystallinities of DSC, the fact that WAXS analysis was carried out over a few superficial microns of the specimens (the skin is usually more amorphous than the core in injection moulded samples) whereas DSC was done on bulk material, and perhaps an additional crystallization induced by polymer chain orientation during sample preparation for DSC. Concerning the annealed samples, which are shown in Figure 3 , at higher crystallization temperatures the reflections of (110/200) and (203) planes shifted to higher $2 \theta$, which suggested that more $\alpha$ and less $\alpha^{\prime}$ crystals were developed in the specimens annealed at higher temperatures ${ }^{22,23}$.

Interestingly, the molecular weight influenced the magnitude of the shift of the main peaks at 16.5 and $18.8^{\circ}$ (Figure 3 and Table 2). The lower the molecular weight of PLA, the higher the shifting to higher $2 \theta$ angles. Since higher $2 \theta$ values can be related to a higher $\alpha / \alpha$ ' crystal ratio, the results suggest that the formation of the more ordered and stable $\alpha$ crystal form is unfavourably affected by increasing the molecular weight of PLA, which confirms the previously mentioned results obtained by DSC.

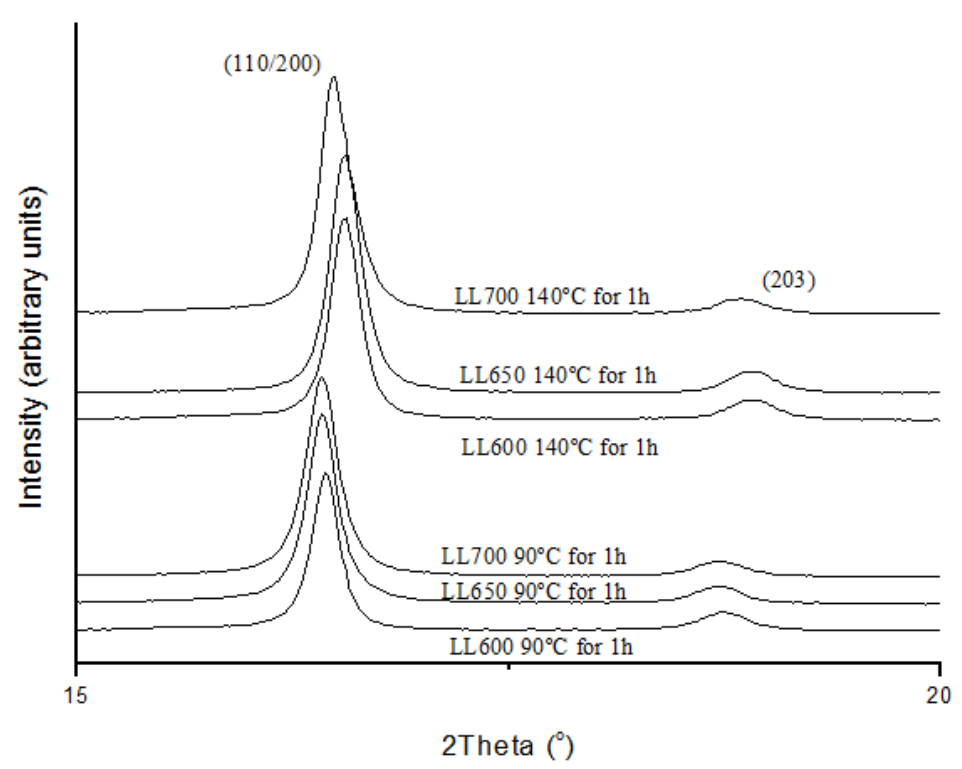

Figure 3. WAXS patterns of different molecular weight PLA samples crystallized at 90 and $140^{\circ} \mathrm{C}$ for $1 \mathrm{~h}$.

Table 2. $2 \theta$ angles related to the reflections of (110/200) and (203) planes. 


\begin{tabular}{|c|c|c|c|}
\hline \multirow{2}{*}{ LL600 } & 1h at $90{ }^{\circ} \mathrm{C}$ & $16.44^{\circ}$ & $18.73^{\circ}$ \\
\hline & $1 \mathrm{~h}$ at $140^{\circ} \mathrm{C}$ & $16.58^{\circ}$ & $18.91^{\circ}$ \\
\hline \multirow{2}{*}{ LL650 } & 1h at $90^{\circ} \mathrm{C}$ & $16.42^{\circ}$ & $18.73^{\circ}$ \\
\hline & 1h at $140^{\circ} \mathrm{C}$ & $16.56^{\circ}$ & $18.89^{\circ}$ \\
\hline \multirow{2}{*}{ LL700 } & 1h at $90^{\circ} \mathrm{C}$ & $16.42^{\circ}$ & $18.71^{\circ}$ \\
\hline & $1 \mathrm{~h}$ at $140{ }^{\circ} \mathrm{C}$ & $16.50^{\circ}$ & $18.84^{\circ}$ \\
\hline
\end{tabular}

\subsubsection{Crystalline micromorphology}

The effect of the molecular weight and the annealing temperature on the resulting morphology was studied by POM. An increase of the spherulite size and decrease of the number of nuclei with increasing the crystallization temperature was detected, which is in accordance with literature ${ }^{24,25}$. As representative images, the morphologies of LL600 films crystallized at 90 and $140{ }^{\circ} \mathrm{C}$ and LL700 crystallized at $140^{\circ} \mathrm{C}$ in a hot stage after cooling from the melt are shown in Figure 4. At high crystallization temperatures (i.e. $140{ }^{\circ} \mathrm{C}$ ) reached from the melt, the nucleation density increased and the spherulite size decreased with increasing the molecular weight of PLA.

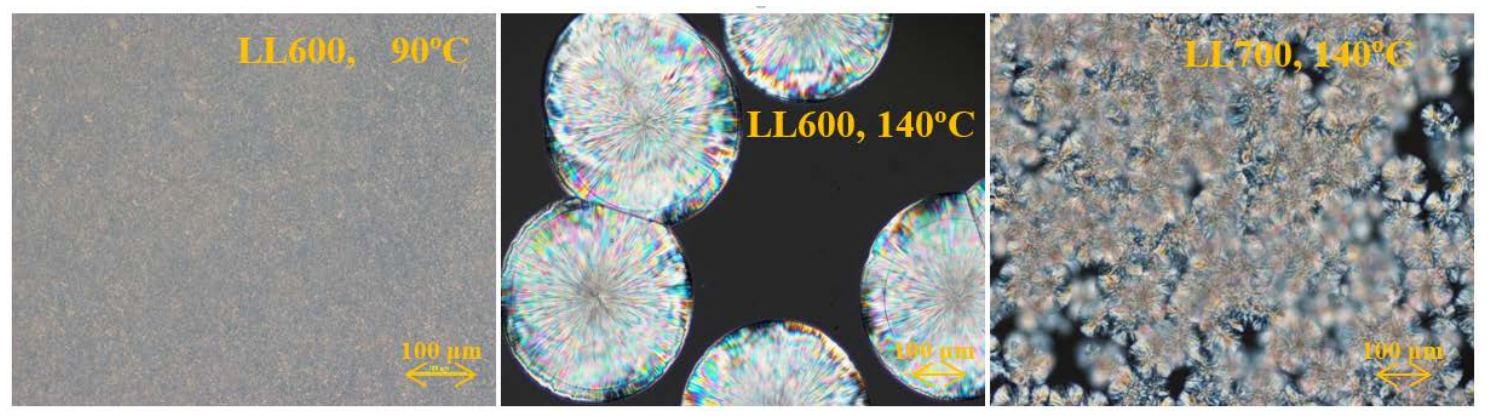

Figure 4. Crystal morphology of LL600 and LL700 crystallized at different annealing temperature after cooling from the melt.

However, it has to be noted that the samples studied by DSC and WAXS were annealed after heating from the glassy state. Hence, the morphology of LL600, LL650 and LL700 films annealed in a hot stage at $90,105,120$ and $140{ }^{\circ} \mathrm{C}$ after being heated from the glassy state at $50{ }^{\circ} \mathrm{C} / \mathrm{min}$ are shown in Figure 5. These results contrasted with the crystalline morphologies that were obtained when crystallizing PLA at isothermal temperatures after cooling from the melt (Figure 4). The crystalline structure of LL600 consisted on a large number of tiny spherulites regardless the annealing temperature. It showed similar morphology when crystallized at $90{ }^{\circ} \mathrm{C}$ from the melt and from the glassy state, but it showed a completely different morphology at $140{ }^{\circ} \mathrm{C}$. This was because the nucleation step of PLA is very fast at temperatures around $90-100{ }^{\circ} \mathrm{C}$, and regardless the sample is cooled or heated up, the nucleation density is defined at this temperature range. As the sample crystallized at $140{ }^{\circ} \mathrm{C}$ from the melt does not pass through the $90-100{ }^{\circ} \mathrm{C}$ range, the nucleation step is carried out at higher temperatures, at which the obtained nucleation densities 
are lower as reported by Pluta and Galeski ${ }^{11}$. Nevertheless, they also reported that that this has no effect on the lamellar structure of the obtained crystals.

On the other hand, LL650 and LL700 exhibited slower crystallization kinetics due to their higher molecular weight and thus lower chain mobility, as seen by POM monitorization. Similar morphologies were detected for these two PLA molecular weights. The obtained morphology varied with the applied annealing temperature, in contrast to LL600. Besides, two different populations of spherulites were formed at 105,120 and $140{ }^{\circ} \mathrm{C}$. First, smaller crystals (similar to those seen for LL600) were formed during the heating scan until reaching the annealing temperature. Then, bigger spherulites started to grow once the sample reached the annealing temperature. The population of bigger spherulites grew in a similar way than for samples crystallized from the melt state. Bigger spherulites were detected together with the increase of the annealing temperature, whereas the size of the population of smaller spherulites remained roughly constant.

Therefore, the morphological differences induced by annealing from the melt or the glassy state were more pronounced in the case of lower molecular weight PLA and at higher crystallization temperatures. Since the nucleation density is higher at lower temperatures and all samples heated up from the glassy state passed through the $90-100^{\circ} \mathrm{C}$ range, nuclei were mostly formed at those temperatures regardless the annealing temperature set in the hot stage.

Thus, for the samples annealed in the range of $105-140{ }^{\circ} \mathrm{C}$ the nuclei were formed at temperatures below the set temperature. This led to similar morphologies for LL600 annealed at all tested temperatures. However, the lower molecular mobility of the higher molecular weight PLAs (LL650 and LL700) might have led to a double population morphology, those nucleated during the heating step and those nucleated once the annealing temperature was reached (105-140 $\left.{ }^{\circ} \mathrm{C}\right)$. 


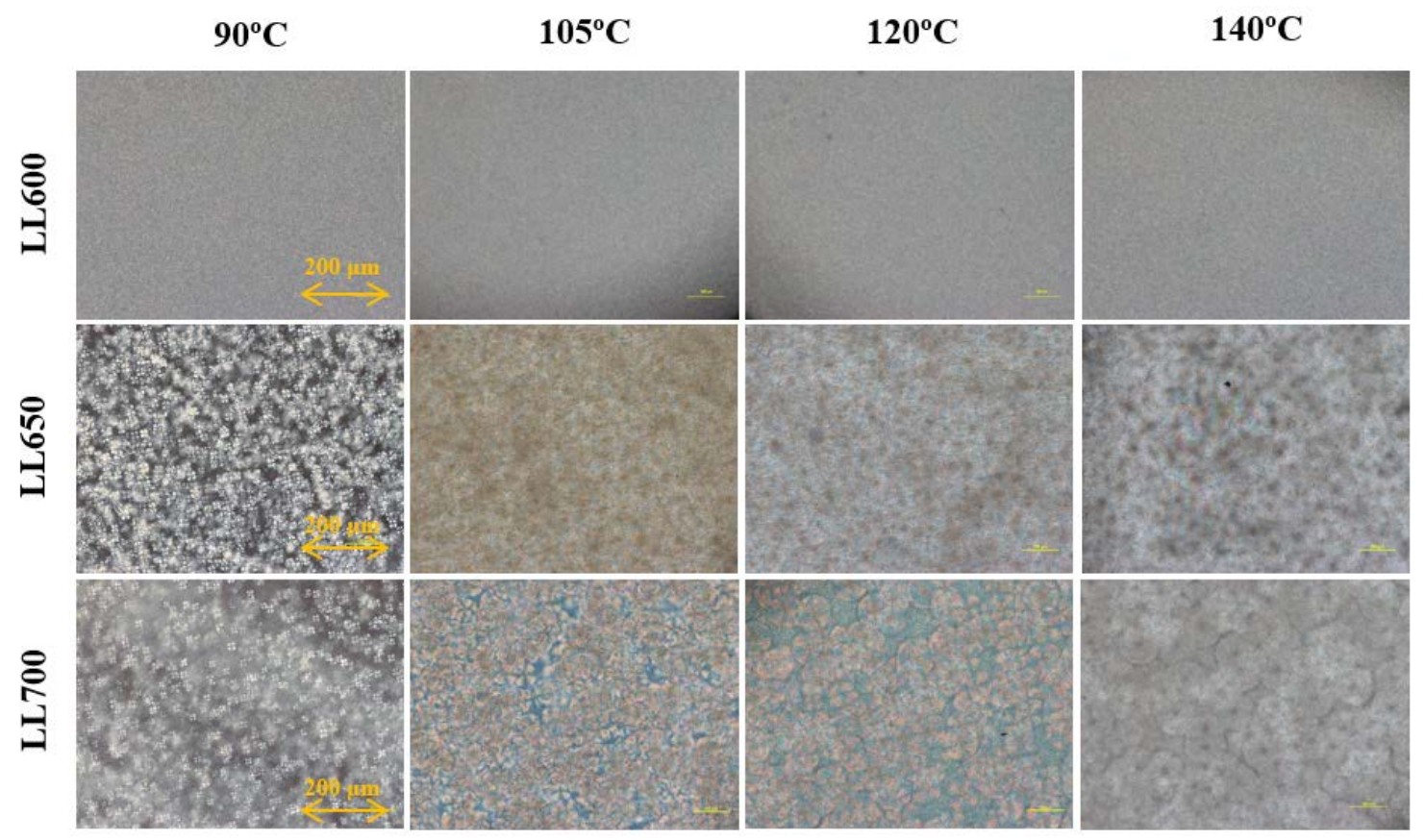

Figure 5. Crystal morphology of different samples of PLA crystallized at various annealing temperatures for 1 hour after being heated from the glassy state.

Table 3 shows the evolution of the bigger sized spherulite population shown for LL650 and LL700 after annealing at different temperatures. Spherulites of LL600 could not be measured due to their tiny size (Figure 5). At $90{ }^{\circ} \mathrm{C}$ the size of the spherulites of LL650 and LL700 was identical while at higher temperatures the spherulites of LL700 grew bigger than those of LL650. This suggested that, due to the lower molecular weight, during the heating step from the glassy state the nucleation density of LL650 was higher than that of LL700. Hence, the bigger sized population of spherulites could grow less for lower molecular weight PLA.

Table 3. Spherulite size of LL650 and LL700 at the impingement.

\begin{tabular}{ccc}
\hline Annealing Temperature $\left({ }^{\circ} \mathbf{C}\right)$ & D LL650 $_{(\mu \mathrm{m})}$ & $\mathbf{D}_{\text {LL700 }}(\boldsymbol{\mu m})$ \\
\hline 90 & 22 & 22 \\
105 & 36 & 62 \\
120 & 55 & 96 \\
140 & 90 & 102 \\
\hline
\end{tabular}


Regarding the effect of the heating rate from the glassy state to the set annealing temperature on the resulting morphology, POM images of LL600 annealed at $140{ }^{\circ} \mathrm{C}$ heated at $50{ }^{\circ} \mathrm{C} / \mathrm{min}$ and heated "instantly" (by placing a film sample in a pre-heated hot stage chamber) can be seen in Figure 6. Images show that the applied heating rate from the glassy state to the annealing temperature has a determining effect on the size and number of the formed spherulites. Increasing the heating rate, the size and number of spherulites increased and decreased, respectively. Hence, the obtained morphology at high heating rates is close to that obtained by cooling the sample from the melt (as it becomes closer to a real isothermal crystallization).
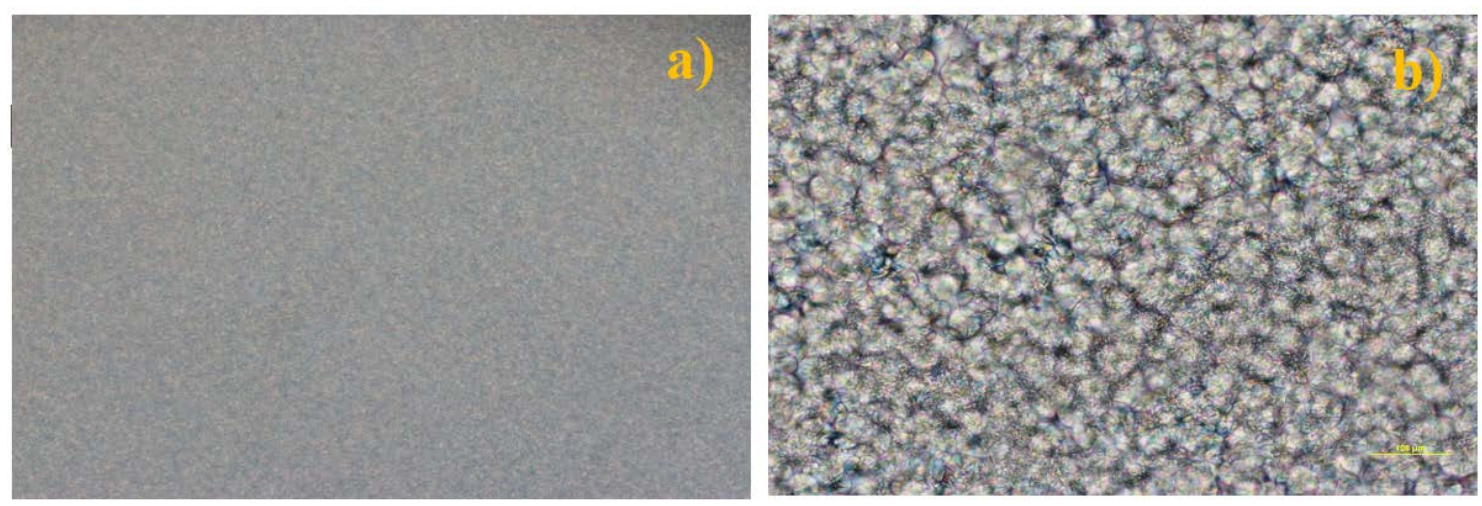

Figure 6. Crystal morphology of LL600 grade crystallized at $140^{\circ} \mathrm{C}$ from the solid state heating from room temperature at a) low heating rate $\left(50^{\circ} \mathrm{C} / \mathrm{min}\right)$ and $\left.\mathrm{b}\right)$ high heating rate.

This indicates that PLA samples cooled down in an identical way from the melt to the glassy state could lead to different crystalline morphologies after a subsequent annealing process, depending on the applied heating rate. Hence, nuclei are at least partially formed while heating from the glassy state to the annealing temperature, and not in the previous cooling step from the melt to the glassy state as suggested in previous works ${ }^{24,25}$. These studies attributed the morphological differences of PLA crystallized from the melt or the glassy state to the formation of many prenuclei during the cooling of the samples to the glassy state. Therefore, different semicrystalline morphologies can be obtained according to the applied annealing process, heating rate, annealing temperature and molecular weight of the PLA.

The heating rate through the specimen section is unknown (specially in thick thermoplastic specimens like those used for tensile testing defined in the ISO 527 standard). Therefore, the nonisothermal step until reaching the set temperature when annealing in a conventional oven is unavoidable ${ }^{24}$. Together with the results reported above, they suggest that the only accurate method to relate any macromechanical property of a PLA sample with its semicrystalline micromorphology is to use samples obtained at the same conditions, i.e. same geometry, preparation and annealing process, for testing and POM analysis.

Figure 7 shows a POM image of the complete cross-section of a microtomized injection moulded tensile specimen (10x4 mm section) after 20 minutes of annealing at $90{ }^{\circ} \mathrm{C}$ (LL700). The 
distribution of the amorphous and crystalline areas is highly affected by the molecular orientation and chain alignment induced by the flow during the previous injection moulding stage. Hence, there is not such a skin-to-core gradient on the crystallinity degree during annealing in the oven but a more complex spiral/concentric amorphous-to-crystalline phase evolution. Even though deeper insight on this issue was not the aim of this work, results suggest that the injection flow induced chain alignment and molecular orientation deeply affect the crystallization process of PLA, which leads to the complex spiral-shaped amorphous/crystalline morphology shown in Figure 7 instead of the typically thought crystallinity gradient from core-to-skin. Hence, controlling the induced chain alignment could be a way to tune the desired crystalline structure.

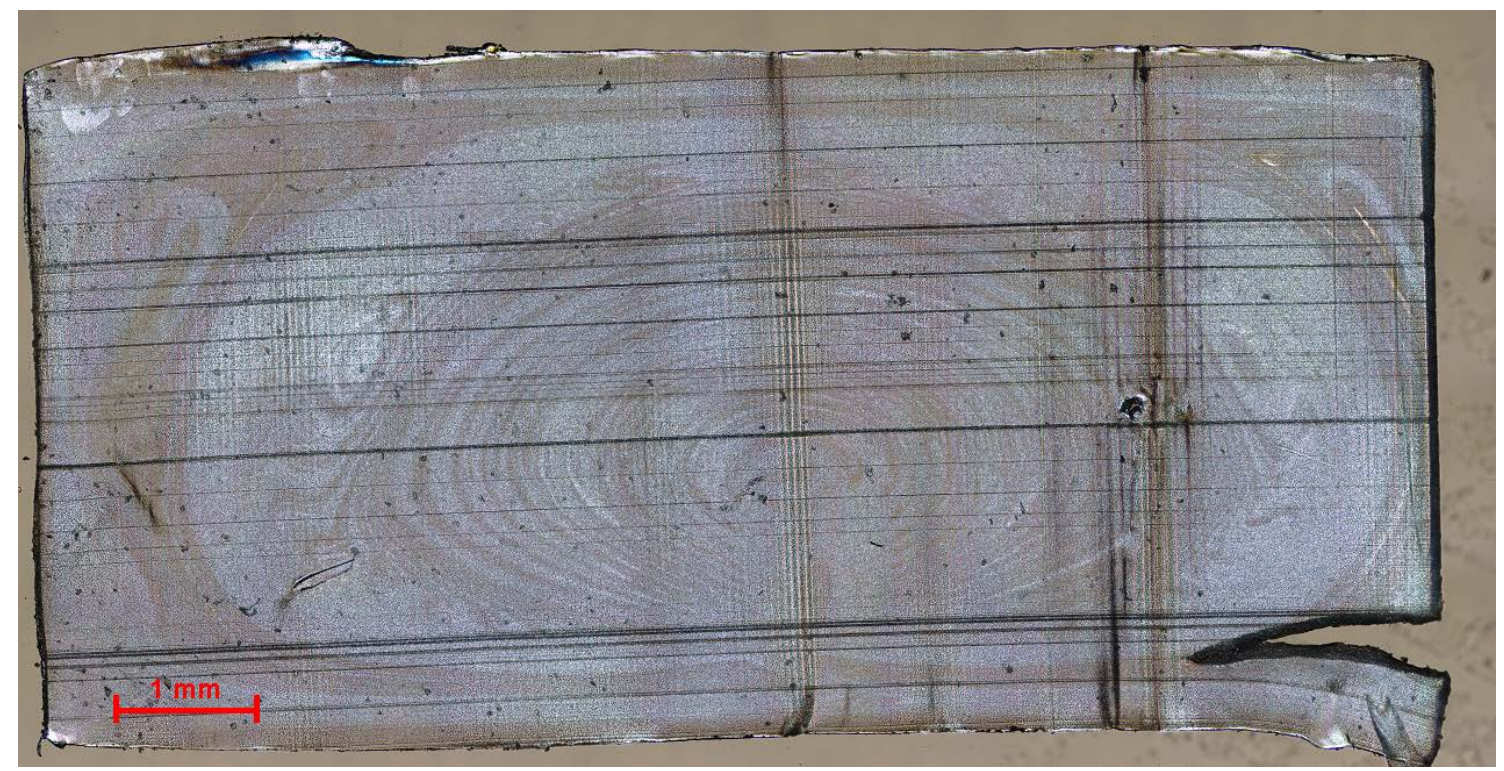

Figure 7. Evolution of the crystalline phase across the section of a tensile sample $(4 \times 10 \mathrm{~mm})$ during annealing of LL700 at $90{ }^{\circ} \mathrm{C}$ for 20 minutes (POM).

Figure 8 shows the POM images of microtomized LL600, LL650 and LL700 tensile test specimens previously annealed at $140{ }^{\circ} \mathrm{C}$ for 1 hour. All samples show densely nucleated and highly crystallized morphologies. At those crystallization levels differences are not easily detectable in terms of spherulite size and nucleation density. Thus, microtomized LL700 samples annealed at 90 and $140{ }^{\circ} \mathrm{C}$ for shorter time (i.e.: 10 or 20 minutes) were analysed (see Figure 9), but these samples showed similar micromorphologies to those obtained for 1 hour (Figure 8).

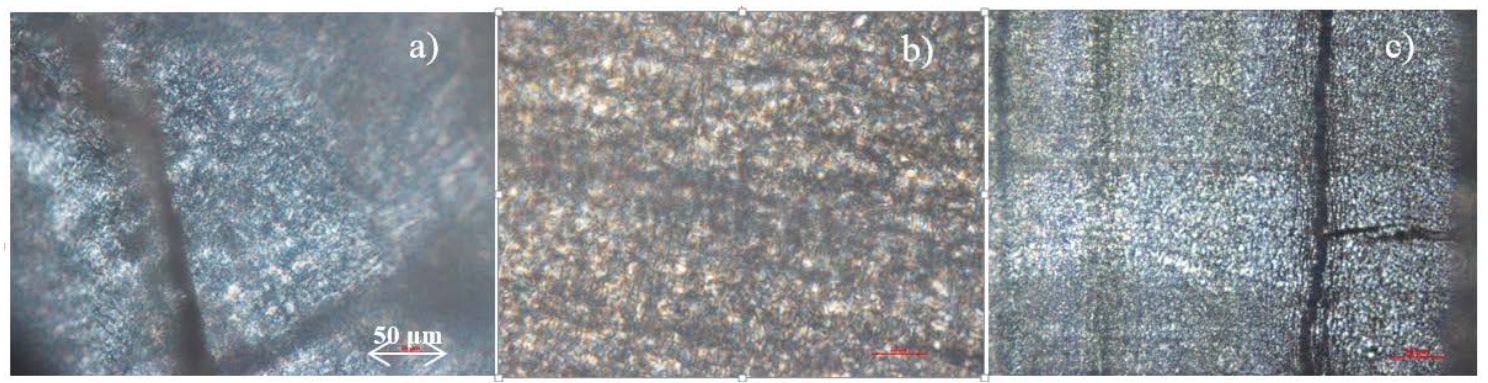

Figure 8. POM images of microtomized samples after being annealed at $140{ }^{\circ} \mathrm{C}$ for 1 hour. a) LL600, b) 
a)

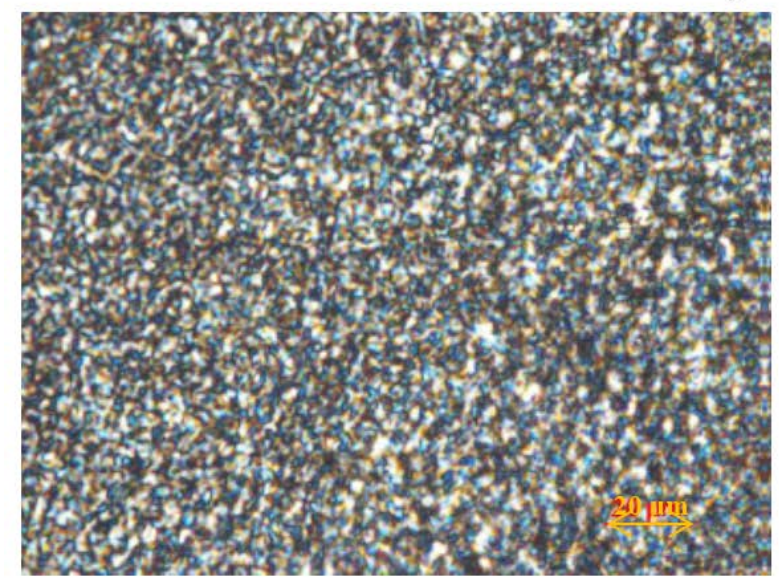

b)

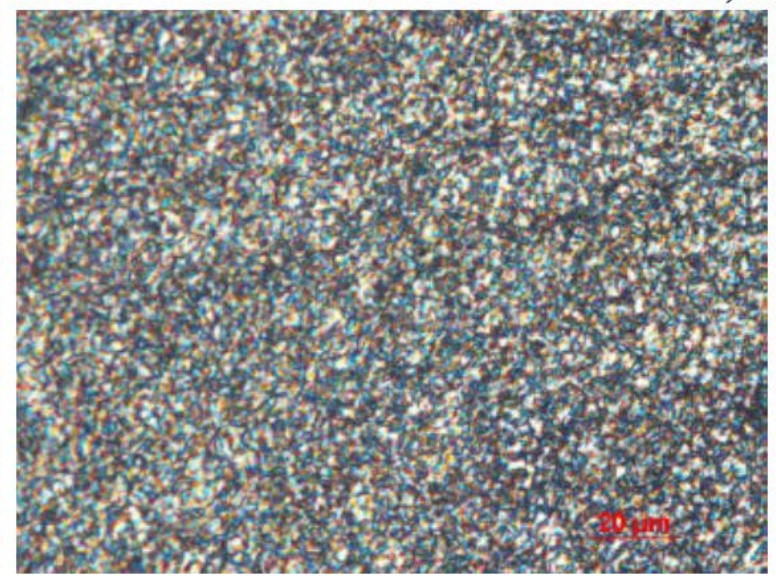

Figure 9. POM images of microtomized LL700 samples previously annealed at a) $90^{\circ} \mathrm{C}$ and b) $140{ }^{\circ} \mathrm{C}$ for 20 minutes.

On the other hand, almost no differences in the micromorphology of samples annealed at 90 and $140^{\circ} \mathrm{C}$ were detected. Regardless the molecular weight of the PLA and the annealing temperature, the micromorphology of PLA for all microtomized testing specimens seemed to be very similar and therefore did not fit with the previous POM results obtained in the hot stage. However, it has to be noted that some samples might have developed bigger spherulites than others, but due to the high crystallinity obtained, those spherulites are not easily measurable after impingement. According to what stated by Tábi et $a .^{22}$, the results obtained from annealed PLA experiments might be used in practice such as using optimal annealing temperature as the optimal mould temperature for injection moulding process, hence leading to in-mould-annealed PLA parts with the desired crystallinity degree and crystal morphology. However, the obtained results have shown that the crystal morphology of PLA can be different depending on whether it is crystallized from the melt or the solid state. Thus, results show the need of a careful sample preparation technique selection in order to be able to relate the results obtained by different techniques such as DSC, WAXS and POM.

Nevertheless, the obtained results suggested that the real heating rate of the polymer in the oven was lower than the $50{ }^{\circ} \mathrm{C} / \mathrm{min}$ applied in the hot stage, thus PLA had time to generate crystal nuclei at lower temperatures. Consequently, the micromorphology of all samples seemed to be similar, showing densely nucleated and highly crystallized micromorphologies, regardless the molecular weight and the annealing temperature.

An additional test was carried out in order to check the morphology of microtomized samples annealed after applying a higher heating rate. LL650 specimens were annealed in silicone oil at $140{ }^{\circ} \mathrm{C}$ for 1 hour. Due to the higher heat conductivity of this oil compared to air, this meant a faster heating of the PLA sample. The micromorphology of a microtomized sample annealed in such conditions is shown in Figure 10. 


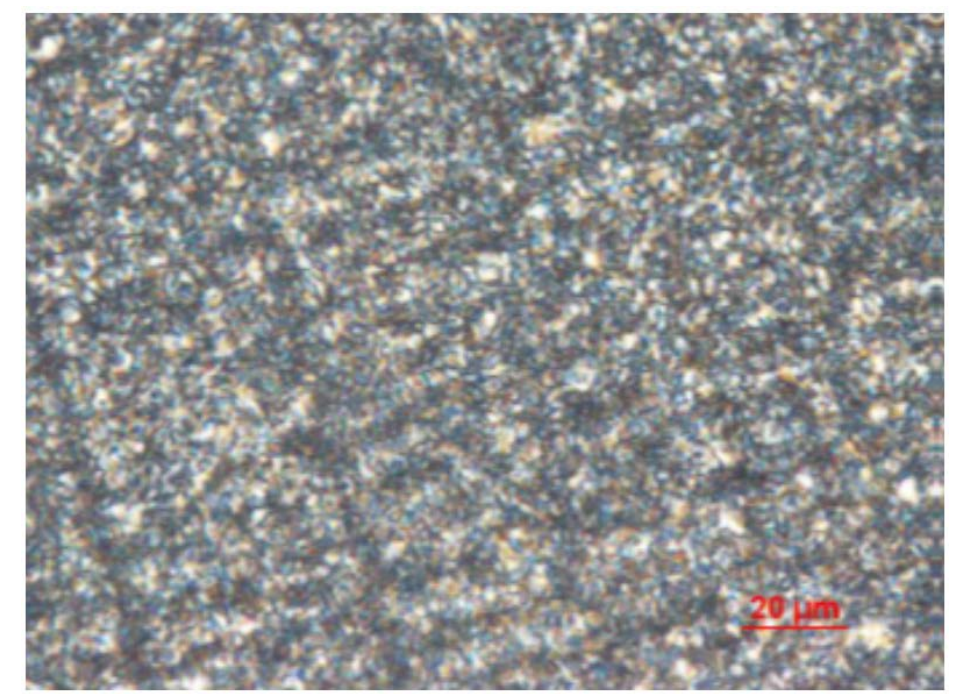

Figure 10. POM images of microtomized LL650 sample previously annealed at $140{ }^{\circ} \mathrm{C}$ for 1 hour in silicone oil.

Although the sample is again highly crystallized and nucleated, its spherulites seem to be bigger than the spherulites of the microtomized samples annealed at $140^{\circ} \mathrm{C}$ for 1 hour in air (Figure 8b). This is in agreement with the previous results obtained for PLA films on the hot stage, which indicated that an increase of the heating rate of the sample resulted in bigger spherulites (Figure $6)$.

\subsubsection{Thermo-mechanical properties}

The evolution of the Heat Distortion Temperature (HDT-A) of LL600, LL650 and LL700 annealed at different temperatures for 1 hour is presented in Figure 11.

The crystallinity degree $\left(\mathrm{X}_{\mathrm{c}}\right)$ of the samples is also reported in the plot. Improvement of the HDTA from around $48{ }^{\circ} \mathrm{C}$ to $63{ }^{\circ} \mathrm{C}$ was detected when comparing unannealed samples to those annealed at $90{ }^{\circ} \mathrm{C}$ regardless the molecular weight. Besides, an increase of the HDT-A was observed together with increasing the annealing temperature. These HDT-A values correlated with higher $\mathrm{X}_{\mathrm{c}}$ values, which is in agreement with literature ${ }^{22}$.

On the other hand, close $\mathrm{X}_{\mathrm{c}}$ and HDT-A values were detected for different molecular weight samples after annealing at the low temperature range (90-110 $\left.{ }^{\circ} \mathrm{C}\right)$. However, at high annealing temperatures (i.e.: 120 and $140^{\circ} \mathrm{C}$ ), LL650 performed the highest heat resistance among the three grades. 


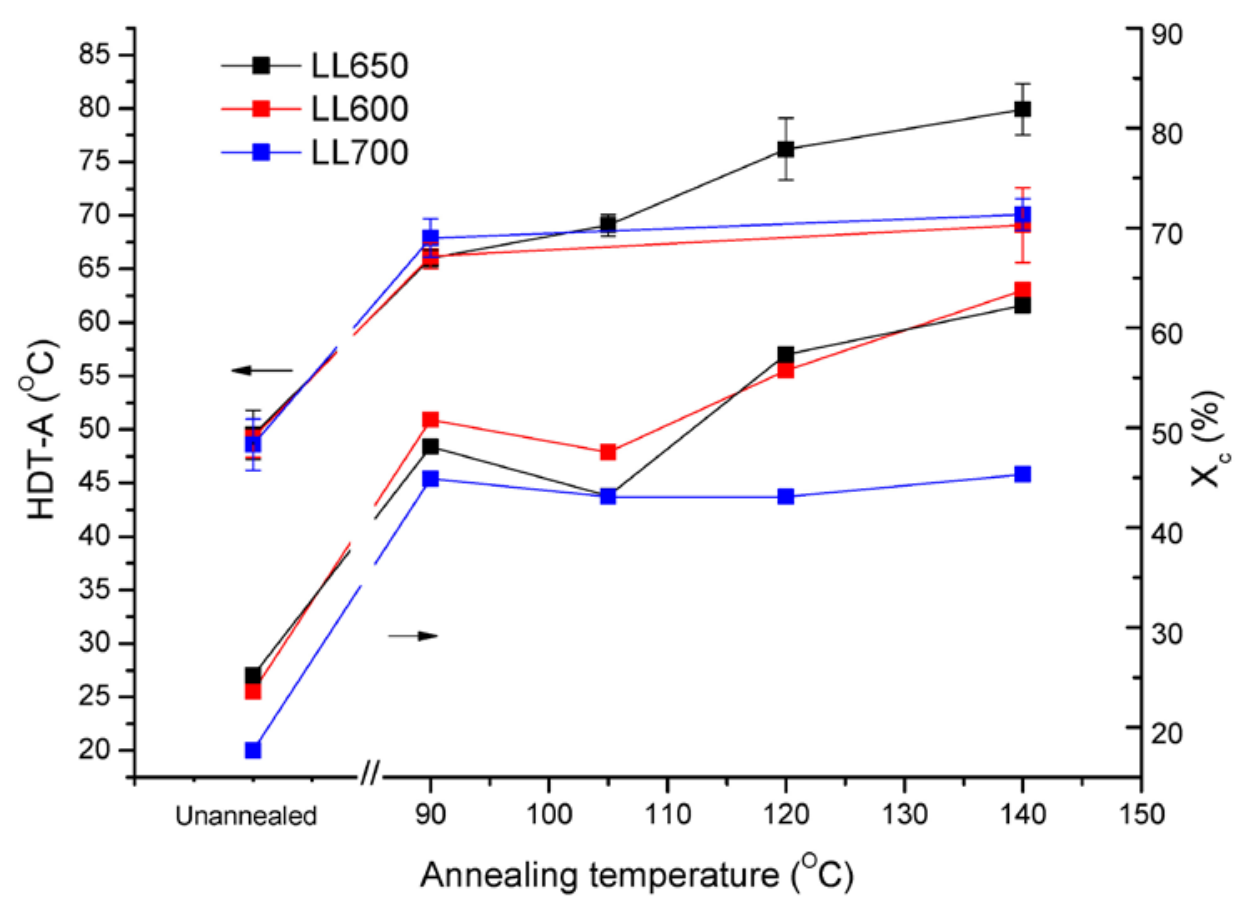

Figure 11. Heat Distortion Temperature (HDT-A) and crystallinity degree of LL600, LL650 and LL700 annealed at 90, 105, 120 and $140{ }^{\circ} \mathrm{C}$ for 1 hour.

On the one hand, LL700 had lower HDT-A because it achieved a lower crystallinity degree than LL600 and LL650 due to its higher molecular weight. Concerning LL600, although having similar crystallinity degree to LL650, it presented lower HDT-A values, close to those of LL700. Besides, POM analysis had shown the similar micromorphology in terms of spherulite size of these samples. It has been reported that the $\alpha / \alpha^{\prime}$ crystal ratio can also affect the thermal resistance, higher ratios leading to higher HDT values ${ }^{22}$. Thus, these results suggested that the lower molecular weight and hence the higher molecular mobility of LL600 lead to a higher nucleation density than LL650 while heating to the annealing temperature in the oven, thus leading to a lower $\alpha / \alpha$.

DSC heating thermograms of LL600, LL650 and LL700 after being annealed for 1 hour at 140 ${ }^{\circ} \mathrm{C}$ showed evidence of the different $\alpha / \alpha$ ' ratio obtained for each PLA grade (Figure 12). The melting peak detected at lower temperature in each case, related to the $\alpha^{\prime}$ to $\alpha$ phase transition, showed to be less important in the case of LL650 than for LL600, indicating a lower amount of $\alpha$ ' crystals. In other words, LL650, even though showing similar micromorphology, seemed to be the only studied sample containing high crystallinity degree $(>60 \%)$ together with a high $\alpha / \alpha$ ' ratio, which made this molecular weight very interesting in order to obtain high heat resistant PLA after an annealing process at elevated temperature $\left(120-140^{\circ} \mathrm{C}\right)$. 


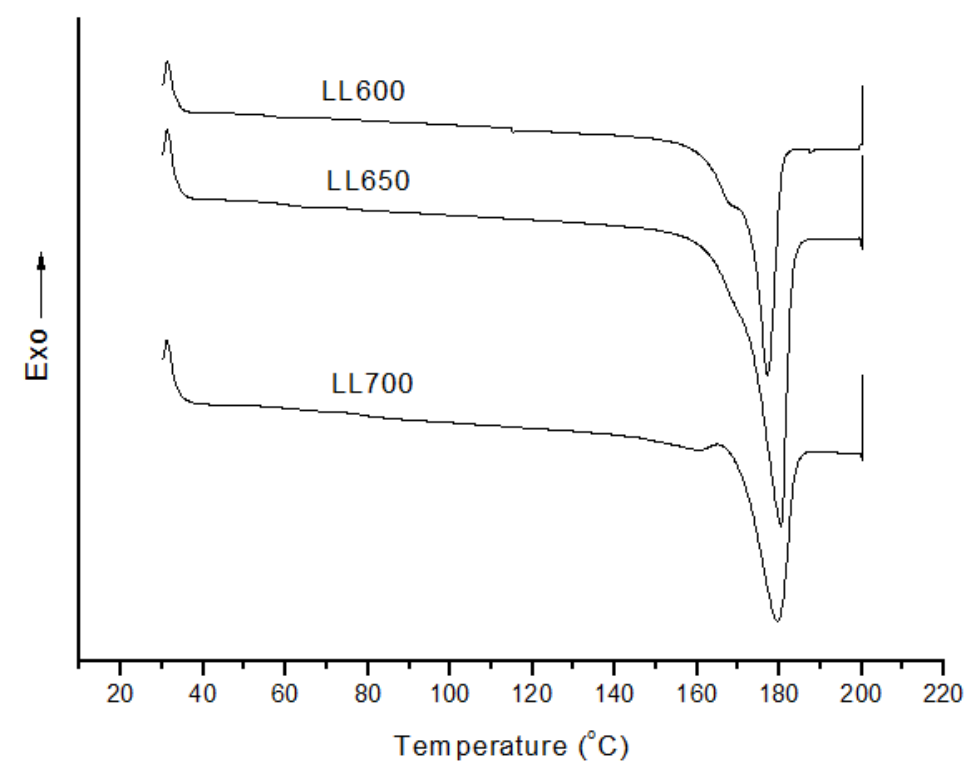

Figure 12. DSC heating thermograms of LL600, LL650 and LL700 annealed for 1 hour at $140{ }^{\circ} \mathrm{C}$.

In order to evaluate the influence of the heating rate on the heat resistance of PLA, HDT-A was also carried out on LL650 specimens annealed at $140^{\circ} \mathrm{C}$ for 1 hour in silicone oil. A mean value of $84.3^{\circ} \mathrm{C}$ was obtained, $4.4{ }^{\circ} \mathrm{C}$ higher than that obtained for specimens annealed at the same conditions in air. The DSC scan of these samples showed a crystallinity degree of $X_{c} \approx 81 \%$, which is $20 \%$ higher than that shown by the sample annealed in air. Therefore, annealing in silicone oil leads to an improvement of the thermo-mechanical properties of PLA, which is caused by the notable increase of the degree of crystallinity, probably together with a higher $\alpha / \alpha$ ' crystal ratio and bigger spherulites size as shown in Figure 10.

For deeper insight of the thermomechanical behaviour of LL650, DMTA analysis was carried out on samples annealed at different temperatures from the glassy state. The evolution of the storage modulus is shown in Figure 13.

For the unannealed sample it remained roughly constant at around $1920 \mathrm{MPa}$ until $\mathrm{T}_{\mathrm{g}}$, at which the storage modulus decreased critically due to the low crystallinity. The increase of the modulus detected above $80^{\circ} \mathrm{C}$ was due to cold crystallization. The decrease in the storage modulus at $\mathrm{T}_{\mathrm{g}}$ was notably lower for the annealed samples. Higher annealing temperatures lead to smaller storage modulus drops, which fits with the previous HDT-A results. Again, this behaviour is explained not in terms of micromorphology (which seemed to be similar for all annealing temperatures), but in terms of the higher crystallinity degree and $\alpha / \alpha^{\prime}$ ratio obtained at higher annealing temperatures. 


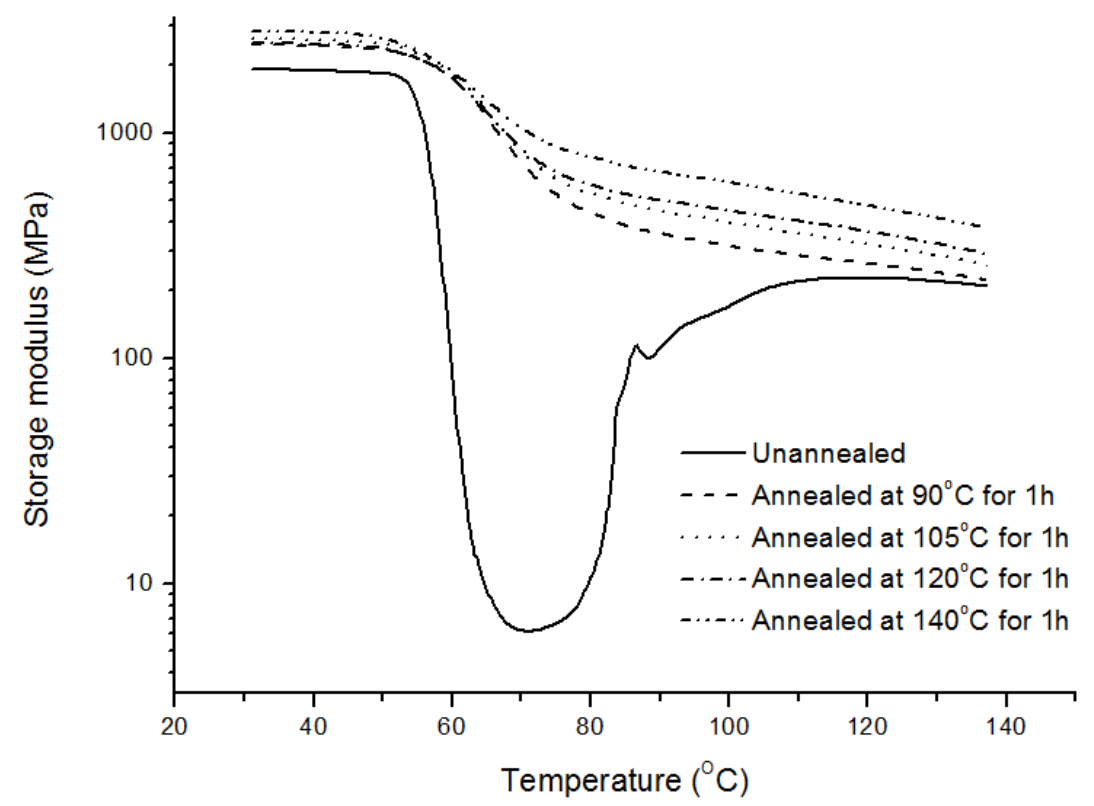

Figure 13. Evolution of the storage modulus of LL650 annealed at 90, 105, 120 and $140{ }^{\circ} \mathrm{C}$ for 1 hour.

\subsubsection{Impact properties}

The three studied PLA grades showed the same trend concerning impact resistance. Samples annealed at $90{ }^{\circ} \mathrm{C}$ showed improved impact resistance compared to the unannealed ones. POM images revealed a large number of tiny spherulites in the morphology of these samples, regardless the molecular weight, which seemed to be an interesting morphology in terms of resulting impact resistance. However, further increase of the crystallization temperature lead to a progressive drop of the impact properties, becoming even lower than what measured for the corresponding unannealed samples (Figure 14).

The loss of impact resistance fairly correlated with the further increase of crystallinity degree of LL600 and LL650 as the annealing temperature was increased from 100 to $140^{\circ} \mathrm{C}$. Indeed, LL700, which showed the lowest crystallinity degree, performed the highest impact resistance among the three PLA grades after being annealed at $140{ }^{\circ} \mathrm{C}$. In any case, the loss of impact resistance seemed to have no direct relationship with the micromorphology of the samples, because no clear difference on spherulite size had been observed among the samples regardless the annealing temperature (Figure 8 and 9). However, the drop of the impact strength of LL700 with increasing the annealing temperature did not correlate with the evolution of the crystallinity degree, since it was kept roughly constant for the whole annealing temperature range. On the other hand, PLA degradation during the annealing process (particularly at high temperatures, i.e. 120 and $140{ }^{\circ} \mathrm{C}$ ) could lead to a loss of impact properties. However, as it can be seen from the GPC chromatograms in Figure 1, there is no significant degradation due to the thermal annealing. Therefore, other factors such as the higher presence of $\alpha$ crystals and the molecular weight itself could have an influence on the measured impact resistances. 


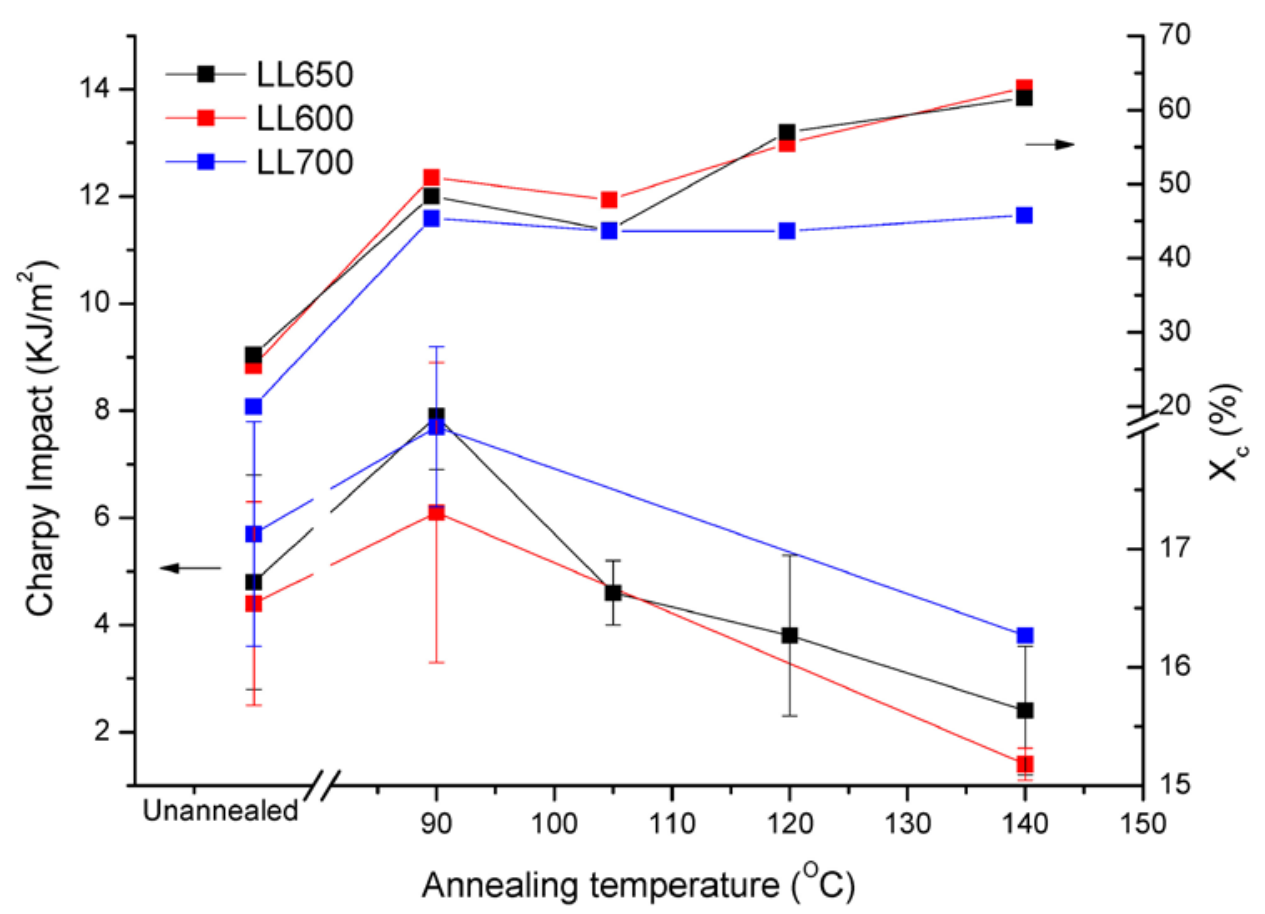

Figure 14. Notched impact resistance of LL600, LL650 and LL700 annealed at 90, 105, 120 and $140{ }^{\circ} \mathrm{C}$ for 1 hour.

\subsection{Conclusions}

Using different types of specimens for different characterization techniques, which might involve different heating rates of the polymeric mass in the oven, or reaching to the desired annealing temperature from the melt or from the glassy state, among others, have been shown to have critical effect on the resulting semicrystalline micromorphology of annealed PLA. At $90{ }^{\circ} \mathrm{C}$ the size of the spherulites of medium (LL650) and high molecular weight PLA (LL700) was identical while at higher temperatures the spherulites of LL700 grew bigger than those of LL650. This suggested that, due to the lower molecular weight, during the heating step from the glassy state the nucleation density of LL650 was higher than that of LL700. Hence, the bigger sized population of spherulites could grow less for lower molecular weight PLA.

The crystal morphology of PLA can be different depending on whether it is crystallized from the melt or the solid state. Therefore, in order to properly relate the morphology with the macromechanical and thermal properties, the use of microtomized samples obtained at the same conditions used for the rest of the characterization is suggested.

On the other hand, the crystalline morphology of PLA can be tuned by controlling the applied annealing process, heating rate, annealing temperature and molecular weight. Indeed, high heat resistant neat PLA (HDT-A $\approx 80^{\circ} \mathrm{C}$ ) can be obtained if a medium molecular weight grade $\left(\mathrm{M}_{\mathrm{n}} \approx\right.$ $110 \mathrm{~kg} \cdot \mathrm{mol}^{-1}$ ) is annealed at around $140{ }^{\circ} \mathrm{C}$ after heating from the glassy state. This enhanced thermal resistance over other molecular weight PLA grades or applied annealing temperatures 
seems to have no relationship with the obtained micromorphology (nucleation density and spherulite size) but with the combined effect of high crystallinity degree and high $\alpha / \alpha$ ' crystal ratio. However, impact resistance decrease with the annealing temperature mainly because of a high $\alpha / \alpha$ ' crystal ratio and crystallinity, whereas morphology or thermal degradation have little or no effect on the increase of the fragility of the material.

\section{Acknowledgements}

The authors would like to thank to Generalitat de Catalunya (Doctorat Industrial DI2014-0021) and Spanish Ministry of Economy and Competitiveness (Program RETOS, Grant No. MAT201680045-R) for the financial support.

\section{References}

1. Auras R, Harte B and Selke S, Macromol Biosci 4: 835-864 (2004). DOI:10.1002/mabi.200400043

2. Belgacem MN and Gandini A, Eds. Monomers, polymers and composites from renewable resources, $1^{\text {st }}$ Edition, Elsevier Limited Publication, Amsterdam, 2008.

3. Institute for Bioplastics and Biocomposites (nova-Institute). European Bioplastics 2014 [www.biobased.eu/markets, date of consultation: October 2017]

4. Saeidlou S, Huneault MA, Li H and Park CB, Prog Polym Sci 37: 1657-1677 (2012). DOI: 10.1016/j.progpolymsci.2012.07.005

5. Kolstad JJ, J Appl Polym Sci, 62: $1079-1091 \quad$ (1996). $\quad$ DOI: $10.1002 /($ SICI)10974628(19961114)62:7<1079::AID-APP14>3.0.CO;2-1

6. Liu Y, Wang L, He Y, Fan Z and Li S, Polym Int, 59: 1616-1621 (2010). DOI: 10.1002/pi.2894

7. Harris AM and Lee EC, J Appl Polym Sci, 107: 2246-2255 (2008). DOI: 10.1002/app.27261

8. Perego G, Cella GD and Bastioli C, J Appl Polym Sci, 59: 37-43 (1996). DOI: 10.1002/(SICI)10974628(19960103)59:1<37::AID-APP6>3.0.CO;2-N

9. Pan P, Kai W, Zhu B, Dong T and Inoue Y, Macromolecules, 40: 6898-6905 (2007). DOI: 10.1021/ma071258d

10. Jalali A, Huneault MA and Elkoun S, J Polym Res, 24: 182 (2017). DOI: 10.1007/s10965-017-1337-x

11. Pluta M and Galeski A, J Appl Polym Sci, 86: 1386-1395 (2002). DOI: 10.1002/app.11280

12. Anakabe J, Huici AZ, Eceiza A, Arbelaiz A, and Avérous L, Polym Bull, 74: 4857-4886 (2017). DOI: 10.1007/s00289-017-1989-z 
13. Na B, Zhu J, Lv R, Ju Y, Tian R and Chen B, Macromolecules, 47: 347-352 (2013). DOI: 10.1021/ma402405c

14. Liu T, Yu X, Yu F, Zhao X, Lu A, Wang J, et al., Polym-Plast Technol Eng, 51: 597-604 (2012). DOI: 10.1080/03602559.2012.659309

15. Nam JY, Sinha Ray S and Okamoto M, Macromolecules, 36: 7126-7131 (2003). DOI: 10.1021/ma034623j

16. Cailloux J, Santana OO, Franco-Urquiza E, Bou JJ, Carrasco F, Gámez Pérez J, et al., Express Polym Lett, 7: 304-318 (2013). DOI: 10.3144/expresspolymlett.2013.27

17. Wang L, Wang Y, Huang $\mathrm{Z}$ and Weng Y, Mater Des, 66: 7-15 (2015). DOI: 10.1016/j.matdes.2014.10.011

18. Xiong Z, Liu G, Zhang X, Wen T, de Vos S, Joziasse C, et al., Polymer, 54: 964-971 (2013). DOI: 10.1016/j.polymer.2012.11.076

19.Pan P and Inoue Y, Prog Polym Sci, 34: 605-640 (2009). DOI: 10.1016/j.progpolymsci.2009.01.003

20. Di Lorenzo ML, Macromol Symp, 234: 176-183 (2006). DOI: 10.1002/masy.200650223

21. Zhang J, Tashiro K, Tsuji H and Domb AJ, Macromolecules, 41: 1352-1357 (2008). DOI: 10.1021/ma0706071

22. Tábi T, Hajba S and Kovács JG, Eur Polym J, 82: 232-243 (2016). DOI: 10.1016/j.eurpolymj.2016.07.024

23. Cocca M, Di Lorenzo ML, Malinconico M and Frezza V, Eur Polym J, 47: 1073-1080 (2011). DOI: 10.1016/j.eurpolymj.2011.02.009

24. Nassar SF, Guinault A, Delpouve N, Divry V, Ducruet V, Sollogoub C, et al., Polymer 108: $163-172$ (2017). DOI: 10.1016/j.polymer.2016.11.047

25. Pluta M, Galeski A, Alexandre M, Paul MA and Dubois P, J Appl Polym Sci 86: 1497-1506 (2002). DOI: 10.1002/app.11309 


\section{List of tables}

Table 1. Crystallinity degree of PLA bars annealed at various temperatures.

\begin{tabular}{cccc}
\hline \multirow{2}{*}{ Annealing conditions } & \multicolumn{3}{c}{ Xc (\%) } \\
\cline { 2 - 4 } & LL600 & LL650 & LL700 \\
\hline As injection moulded & 25.5 & 27.0 & 20.0 \\
$90^{\circ} \mathrm{C}$ at $1 \mathrm{~h}$ & 50.9 & 48.4 & 45.4 \\
$105^{\circ} \mathrm{C}$ at $1 \mathrm{~h}$ & 47.9 & 43.8 & 43.7 \\
$120^{\circ} \mathrm{C}$ at $1 \mathrm{~h}$ & 55.5 & 57.0 & 43.7 \\
$140^{\circ} \mathrm{C}$ at $1 \mathrm{~h}$ & 63.0 & 61.6 & 45.8 \\
\hline
\end{tabular}


Table 2. $2 \theta$ angles related to the reflections of (110/200) and (203) planes.

\begin{tabular}{|c|c|c|c|}
\hline PLA Grade & Annealing conditions & $2 \theta$ (planes $110 / 200)$ & $2 \theta$ (plane 203) \\
\hline \multirow{2}{*}{ LL600 } & $1 \mathrm{~h}$ at $90{ }^{\circ} \mathrm{C}$ & $16.44^{\circ}$ & $18.73^{\circ}$ \\
\hline & $1 \mathrm{~h}$ at $140^{\circ} \mathrm{C}$ & $16.58^{\circ}$ & $18.91^{\circ}$ \\
\hline \multirow{2}{*}{ LL650 } & $1 \mathrm{~h}$ at $90^{\circ} \mathrm{C}$ & $16.42^{\circ}$ & $18.73^{\circ}$ \\
\hline & $1 \mathrm{~h}$ at $140^{\circ} \mathrm{C}$ & $16.56^{\circ}$ & $18.89^{\circ}$ \\
\hline \multirow{2}{*}{ LL700 } & $1 \mathrm{~h}$ at $90^{\circ} \mathrm{C}$ & $16.42^{\circ}$ & $18.71^{\circ}$ \\
\hline & $1 \mathrm{~h}$ at $140^{\circ} \mathrm{C}$ & $16.50^{\circ}$ & $18.84^{\circ}$ \\
\hline
\end{tabular}


Table 3. Spherulite size of LL650 and LL700 at the impingement.

\begin{tabular}{ccc}
\hline Annealing Temperature $\left({ }^{\circ} \mathrm{C}\right)$ & DLL650 $_{(\boldsymbol{\mu m})}$ & DLL700 $(\boldsymbol{\mu m})$ \\
\hline 90 & 22 & 22 \\
105 & 36 & 92 \\
120 & 55 & 96 \\
140 & 90 & 102 \\
\hline
\end{tabular}




\section{Figure legends}

Figure 1. GPC chromatograms of different molecular weight PLA grades: before (solid) and after (dash) annealing at $140^{\circ} \mathrm{C}$ for 1 hour.

Figure 2. DSC heating thermograms of LL600 annealed for 1 hour at different temperatures.

Figure 3. WAXS patterns of different molecular weight PLA samples crystallized at 90 and $140{ }^{\circ} \mathrm{C}$ for 1 h.

Figure 4. Crystal morphology of LL600 and LL700 crystallized at different annealing temperature after cooling from the melt.

Figure 5. Crystal morphology of different samples of PLA crystallized at various annealing temperatures for 1 hour after being heated from the glassy state.

Figure 6. Crystal morphology of LL600 grade crystallized at $140{ }^{\circ} \mathrm{C}$ from the solid state heating from room temperature at a) low heating rate $\left(50^{\circ} \mathrm{C} / \mathrm{min}\right)$ and $\left.\mathrm{b}\right)$ high heating rate.

Figure 7. Evolution of the crystalline phase across the section of a tensile sample $(4 \times 10 \mathrm{~mm})$ during annealing of LL700 at $90{ }^{\circ} \mathrm{C}$ for 20 minutes (POM).

Figure 8. POM images of microtomized samples after being annealed at $140{ }^{\circ} \mathrm{C}$ for 1 hour. a) LL600, b) LL650 and c) LL700.

Figure 9. POM images of microtomized LL700 samples previously annealed at a) $90{ }^{\circ} \mathrm{C}$ and b) $140{ }^{\circ} \mathrm{C}$ for 20 minutes.

Figure 10. POM images of microtomized LL650 sample previously annealed at $140{ }^{\circ} \mathrm{C}$ for 1 hour in silicone oil.

Figure 11. Heat Distortion Temperature (HDT-A) and crystallinity degree of LL600, LL650 and LL700 annealed at 90, 105, 120 and $140{ }^{\circ} \mathrm{C}$ for 1 hour. LL600: circles; LL650: squares; LL700: triangles.

Figure 12. DSC heating thermograms of LL600, LL650 and LL700 annealed for 1 hour at $140{ }^{\circ} \mathrm{C}$.

Figure 13. Evolution of the storage modulus of LL650 annealed at 90, 105, 120 and $140{ }^{\circ} \mathrm{C}$ for 1 hour.

Figure 14. Notched impact resistance of LL600, LL650 and LL700 annealed at 90, 105, 120 and $140{ }^{\circ} \mathrm{C}$ for 1 hour. LL600: circles; LL650: squares; LL700: triangles. 